\title{
THE IMPACT OF GENERAL EDUCATION IN ENHANCING THE SELF- EFFICACY OF ACCOUNTING STUDENTS AT UNIVERSITIES OF TECHNOLOGY
}

\author{
S. K. Naidoo*
}

Department of Management Accounting

https://orcid.org/0000-0001-5980-8256

\section{S. Govender*}

External Research Supervisor

*Durban University of Technology

Durban, South Africa

\section{ABSTRACT}

The aim of this article is to investigate the integration of General Education in improving the Selfefficacy of Cost and Management Accounting (CMA) students to assess whether Self-efficacy, is having any positive impact on the students' academic performance. The research design of this article was descriptive, longitudinal and employed a mixed-method approach. The nature of the quasi-experimental approach that was used in the current article is a non-equivalent pre-test and post-test control group design. The target population was CMA students. A census survey was performed. Findings, which were analysed with the aid of descriptive statistics, indicate a significant correlation in the post-test (Self-efficacy) scores of the group that undertook the General Education Modules and not the group that did not undertake the General Education Modules. This article recommends the implementation of General Education skills into the curriculum and a General Education intervention strategy. Moreover, these skills appear to be very poor amongst current learners and respondents believed that Self-efficacy could have a positive effect on the academic performance of learners.

Keywords: management accounting, financial accounting, general education skills, critical thinking skills, language proficiency, literacy skills, self-efficacy

\section{INTRODUCTION}

The research article focuses on the relationship between six main components of General Education, namely written communication, oral communication, critical thinking, quantitative analysis, science, understanding and computer literacy, on the self-efficacy of learners or their beliefs in accounting studies. In an email communication on 5 December 2014, the ViceChancellor of DUT states that the inclusion of the General Education component will change the nature of education within the institution. General Education would be part of a process that 
is responsible for the formation of the entire undergraduate programme from first to final year and may be included as stand-alone modules or embedded within programme or faculty modules. This study therefore seeks to investigate the impact of General Education on enhancing the Self-efficacy of accounting learners.

The rationale for the study is that the majority of children in South Africa are taught in an African home language from Grade $\mathrm{R}$ to Grade 3 and then suddenly turn to English as an instructional medium in Grade 4 (Evans and Cleghorn 2014, 3). The aim of the sudden switch to English as an instructional tool was to ensure that the children first had a solid literacy base in their mother tongue. Nevertheless, in urban areas some children learn from the beginning of their education in their second language. Learners are under the impression that a superficial understanding of Mathematics and Accounting are the only things you will need to be successful in the accounting sector (Floyd 2014, para. 7 line 1). In addition to formal training, such as gaining a degree in business and Accounting, accountants generally need a range of skills to be able to continue and keep up with the accounting sector changing demands. Such capabilities include good interpersonal contact, customer service, critical thought, analysis and writing (Floyd 2014, para. 7 line 4). All these afore mentioned skills are components of General Education.

\section{GENERAL EDUCATION AT SCHOOL LEVEL}

The present section will focus on the learners and teachers' understanding of the subject matter on Mathematics and language proficiency.

\section{Teacher knowledge of mathematics}

In a study, teachers were required to complete a SACMEQ Mathematics test consisting of 42 items grouped into five mathematical layers: numerical activities; fractions, ratios and percentages; algebraic rationale; rate of change; and location and form. The results on the mathematics test for the South African teachers in comparison with those of the SACMEQ example is illustrated in Table 1.

The teacher test scores percentages in both Language and Mathematics indicate that in South Africa, the Western Cape is in some way the top performing province. However, the picture is different when comparing the top province of South Africa with other African countries. Kenyan teachers, for example, outscore Western Cape teachers with a significant margin in Maths (Taylor, Van der Berg, and Mabogoane 2012, 20). 
Table 1: Teacher Percentage Scores on Maths Test

\begin{tabular}{|l|c|c|c|c|c|c|}
\hline & $\begin{array}{c}\text { Arithmetic } \\
\text { operations }\end{array}$ & $\begin{array}{c}\text { Fractions, } \\
\text { ratio and } \\
\text { proportion }\end{array}$ & $\begin{array}{c}\text { Algebraic } \\
\text { logic }\end{array}$ & $\begin{array}{c}\text { Rate of } \\
\text { change }\end{array}$ & $\begin{array}{c}\text { Space and } \\
\text { shape }\end{array}$ & Total \\
\hline SACMEQ & 69.55 & 57.65 & 48.75 & 44.47 & 66.33 & 57.47 \\
\hline SA & 67.15 & 49.68 & 46.51 & 42.30 & 56.44 & 52.39 \\
\hline
\end{tabular}

Source: Taylor, Van der Berg and Mabogoane $(2012,21)$ (Adapted)

Many of the South African Grade 6 mathematics teachers' subject knowledge base is insufficient to provide a pivotal understanding of the discipline to the learners. Taylor, Van der Berg and Mabogoane $(2012,20)$ suggest that despite the fact that many of the aspects in the teacher test are centred on knowledge not in the curriculum of primary school, it appears that teachers gain awareness through concepts, procedures and demonstrations to provide students with a versatile, conceptual understanding. The results of the test indicate that teacher performance on knowledge that is not in the primary school curriculum is inadequate and not much adequate on a number of crucially important topics that are exclusively in the Grade 6 curricula.

\section{Student knowledge of mathematics}

Between 2011 and 2013, the number of passes obtained by learners in mathematics improved. There was also a sharp drop in the pass rate in 2014 . The proportion of all those candidates having passed Mathematics at 40 per cent between 2011 and 2013 has risen from 30.1 per cent to 40.5 per cent. There was likewise a decrease in the year 2014 to 35.1 per cent for applicants/students who passed Mathematics at 40 per cent. Moreover, there was a decrease in the number of candidates writing Mathematics from 241509 in 2013 to 225458 in 2014. The 5.4 per cent drop in candidates who passed Mathematics at 40 per cent and the declining number of 16051 learners writing Mathematics in 2014 remains a great concern. Table 2 outlines the overall achievements in Mathematics by learners.

Table 2: Learner Pass Rate in Mathematics

\begin{tabular}{|c|c|c|c|c|c|}
\hline Year & $\begin{array}{c}\text { No. } \\
\text { Wrote }\end{array}$ & $\begin{array}{c}\text { No. achieved at } \\
\mathbf{3 0} \text { per cent and } \\
\text { above }\end{array}$ & $\begin{array}{c}\text { Per cent achieved at } \\
\mathbf{3 0} \text { per cent and } \\
\text { above }\end{array}$ & $\begin{array}{c}\text { No. achieved at } \\
\mathbf{4 0} \text { per cent and } \\
\text { above }\end{array}$ & $\begin{array}{c}\text { Per cent } \\
\text { achieved at 40 } \\
\text { per cent } \\
\text { and above }\end{array}$ \\
\hline $\mathbf{2 0 1 1}$ & 224635 & 104033 & 46.3 & 61592 & 30.1 \\
\hline $\mathbf{2 0 1 2}$ & 225874 & 121970 & 54.0 & 80716 & 35.7 \\
\hline $\mathbf{2 0 1 3}$ & 241509 & 142666 & 59.1 & 97790 & 40.5 \\
\hline $\mathbf{2 0 1 4}$ & 225458 & 120523 & 53.5 & 79050 & 35.1 \\
\hline
\end{tabular}




\section{Language proficiency}

An overwhelming majority of South African parents want their children to undertake English channel schools and the use of English as a language of education (De Klerk 2000, 203), although most of these parents have limited knowledge of the English language themselves. Tshotsho $(2006,2)$ contends that those parents prefer English as an instructional medium because of its popularity as the primary language of Science and Technology and its significance for providing contact across cultural barriers, both locally and internationally. Ngidi $(2007,87)$ further endorsed the results, pointing out that parents in South Africa have a positive attitude towards the use of English, as it a globally recognized language with a positive influence for better job prospects. Rammala $(2002,200)$ indicates that despite teachers having a limited level of competence in English, a majority of parents still prefer English medium schools for their children.

Fakeye and Yemi $(2009,490)$ suggest that excellence in the English language is a strong predictor and a positive contributor to academic achievement. Cheng's $(2007,588)$ research on instructional development in the accounting domain at universities emphasizes the importance of English when it is included in the course syllabus. Rauchas et al. (2006) assert that the language courses learned in high school have become greater reliable indicators of academic achievement at tertiary level.

In South Africa, although not proven statistically (only 9.6 per cent of people within the country have English as a home language), English is viewed as a dominant language only in the media, commerce, politics and international communication. NEEDU $(2013,41)$ points out that there were several well-organized and well-stocked reading corners regarding the display of books in the classrooms, but by contrast, many other classrooms contained very few books. NEEDU $(2013,42)$ suggests that in many such schools, the "reading corner" status points to the teacher's general apathy and disinterest in promoting learner literacy. The lack of reading from learners will have an impact on their comprehension skills, language proficiency and ultimately on their tertiary education for the reason that a majority of the tertiary institutions' examination papers are usually in English and responded to in English. However, in addition to the lack of language skills, many South African students consider English their second language and that this poses an obstacle for these students from achieving good results in the test.

\section{Language proficiency of learners}

There seems to be a strong link between the learning of language by pupils in their primary years and their ability to learn, and that it should happen at an extremely young age (CDE 2014, 
16). Learning comes into play via the language medium, but if either teachers or the learners are not knowledgeable in the Language of Learning and Teaching (LoLT), then learning is exceptionally difficult.

At the beginning of their formal education, a number of South African youngsters are educated in their native language and would then move to another language of learning and teaching throughout Grade 4 (CDE 2014, 16; Taylor and Coetzee 2013, 1; Surty 2011, 10 and Gardiner 2008, 20). The "different language" that the authors are referring to is normally English. Surty $(2011,10)$ points out that although learners change the language of teaching and learning from Setswana to English at Grade 4 and switch to English at this stage would be at a significant disadvantage to learners when it comes to literacy and numeracy accomplishment and academic development.

Several schools have picked out English or Afrikaans as the LoLT for a prompt start to ensure a smooth transition, even as early as Grade 1 (NEEDU 2013, 38; Taylor and Coetzee 2013 , 1). However, in public schools, particularly in towns and villages such as Soweto in which many African languages are spoken, it would be challenging for a school to decide on a native language for making the LoLT and it therefore often chooses English (CDE 2014, 16). Research carried out by Taylor and Coetzee $(2013,3)$ highlights a strong link regarding English teaching in grades 1, 2 and 3 and English success in levels 4, 5 and 6.

The influence in changeover of learners taught in their mother tongue to a different language of learning and their language proficiency lays in the performance of learners' matric results. The matric pass rate might have improved, but any optimism about the matric results for 2016 may very well be inappropriate. Swanepoel $(2017,1)$ highlights that basic education minister Angie Motshekga states that the improvement in the rate of matric passes from 70.7 per cent in 2015 to 72.5 per cent in 2016 points that the academic structure is moving in the right direction. Swanepoel $(2017,1)$ indicates that even the average scores for non-scientific subjects does not demonstrate the enthusiasm of a higher pass rate:

- $\quad$ English home language: 54.7 per cent average mark (107 967 candidates with a pass level of 94 per cent) and

- $\quad$ English first additional language: 49 per cent average mark (547 292 with a pass amount of 97.4 per cent).

Tshepo Motsepe, Secretary-General of NGO Equal Education emphasises that matric outcomes are not valid due to the fact that they only display the grades of those who have been able to stay in the program for 12 years and do not disclose how many dropped out of the school system (Swanepoel 2017, 1). 


\section{Language proficiency of teachers}

According to Taylor, Van der Berg and Mabogoane (2012, 20), Grade 6 language teachers did not perform well on the SACMEQ reading test. Teachers performed much better on topics that needed little more than the extraction of specifically mentioned material in the document. The output generally fell as soon as complex cognitive mechanisms became necessary to respond to questions. There were some good scores recorded on items requiring straightforward inferences, but regarding matters, involving interpretation and evaluation were usually very poorly completed.

Nel and Muller $(2010,646)$ highlight that if the medium of exchange of information is unclear and impeded by poor English skills on the part of both the learner as well as the teacher, then the transfer of knowledge can often not be successful. The researchers also note that the language problems that new teachers frequently face include the school's LoLT; questionable informal access of learners to English; the expectations of teachers regarding their own needs; and English skills. The researchers also point out that teacher's preconceived notions of the degree of support they offer to ESL pupils, their interpretations of a multicultural learner's differentiated performance evaluation and insufficient availability of ESL services contribute to language issues.

\section{Language and mathematics relationship}

Abedi and Lord $(2001,219)$ claim that language plays a significant role in the achievement of Mathematics, as learners are required to understand word problems. Perhaps unsurprisingly, one of the main elements that negatively impacts South African Mathematics excellence has been identified as limited English between some of teachers and pupils throughout the LoLT (Zenex Foundation 2007, 6).

Hofmeyr $(2012,1)$ states that it is important to have what experts call "Cognitive Academic Language Proficiency" (CALP). CALP is a skill level that allows for the mastering of abstract concepts and technical language. With the absence of CALP in English, learners in mathematics and science cannot achieve high grades and teacher-training programmes have some degree of impact on pupil performance (Hofmeyr 2012, 1). In 2012, NEEDU $(2013,34)$ evaluators highlighted that many foundation-level teachers who favoured the English method of home language thought that subject-definite expressions made learning Mathematics problematic in a language not in English.

\section{Reading proficiency}

Reading is one of the most essential skills that children learn in the early childhood years. As 
soon as children can read, it is possible for that child to undertake independent solitary work. It is very disturbing that there is a non-present reading culture in rural towns and communities (Gardiner 2008, 21). Children can gradually be familiarised into non-oral forms of speech, the principles of which are frequently contradictory to those of oral types. However, school reading is also completely separate from non-school reading (Bernstein 2003, 204). With an improved readability, the child is less reliant on the teacher and therefore has access to different points of view. Children who are not able to comply with sequential instructions become more reliant on the instructor and on the oral forms of discourse (Bernstein 2003, 204).

Perumal's $(2009,38)$ research on integrated academic performance in South Africa claims that small towns and rural communities were inadequate and lacked the tools to act properly as centres of learning. It would be difficult to find material in printed form; very little to no books, magazines or newspapers in home environment or other areas; and libraries are non-existent (Gardiner 2008, 21). The language landscape in small towns and rural communities seem to be affluent in one or two languages, according to Gardiner $(2008,21)$, but that affluence is part of a specific standard of living, which may not consist of much that is up-to-date and modern. Language skills rely on overcoming obstacles, attempting to find ways to talk, read, and write about the new and perhaps even the unfamiliar. An area without resources cannot promote the development of languages.

There is nothing expected of Grade 2 learners in relation to reading fluency in view of the fact that there are no reading norms established for South African pupils. However, there is an instrument with a comprehensive rigorous set of standards developed for American pupils, where the top learners in Grade 2 read at an overall rate of about 125 words a minute by midyear. According to NEEDU $(2013,39)$, an average learner reads in the region of about 70 words a minute, while slower learners read at an average speed about 20 words a minute.

The outcomes from NEEDU'S reading research suggest that reading confidence and aptitude in both the Foundation and Intermediate stages is alarmingly low and constitutes a national crisis. Poor reading fluency and proficiency could therefore certainly affect other grades of schooling. CDE $(2014,16)$ highlights that learners' poor reading skills have also been receiving awareness from the South African language researchers in Mathematics instruction examining the relationships concerning learners' language skills, especially in English, and their ability to read and perform in Mathematics.

\section{Writing in mathematics}

The impact on the quality and quantity of learners' writing in Mathematics is not well studied in South Africa and the significance of writing is only starting to be realised. The CAPS official 
documents are consistent about the amount and type of writing that learners anticipate in academic subjects such as language, but not so in Mathematics.

Taylor $(2011,7)$ highlights that writing in South African classrooms, particularly for children from poor homes, seldom took place and that this lack of writing must be characterised as one of the huge weaknesses in the schooling system. Taylor $(2011,3)$ goes on to state that a huge and statistical but substantial negative influence on literacy grades happens when no paragraph length writing takes place over a period of one year and that a more positive influence was found when more than 27 writing exercises of all types were counted in learners' English workbooks.

The low number of learners who write in Mathematics is correspondingly a concern. In 2012, NEEDU conducted an assessment on the Foundation Phase in urban schools that focussed on the amount of learners exercise-writing books in Mathematics. NEEDU $(20012,47)$ highlights that majority of classes that have being visited, it was noted that far too little writing was undertaken and there was not enough progress relating to the quantity of writing as learners moved from Grade 1 to Grade 3.

\section{Writing skills}

A CIMA career demands that learners be skilled in writing reports, achieved by academic writing. Management reporting is about supplying statistics within an organization to people that guide and influence its operation. Taylor, Van der Berg and Mabogoane $(2012,13)$ state: "The degree to which information is re-formulated or manipulated through writing has an impact on how well the information is integrated, learned and retained". Reports have to be written to those within the organization for planning, budgeting, motivating of staff and performance evaluation. Much emphasis is placed on decisions affecting the future and timeliness of information is essential. Management Accounting therefore provides crucial data with which the organization actually operates.

Ramos $(2010,31)$ points out that reading strategies and writing skills have a positive correlation. Such results show that reading strategies are worthwhile predictors of writing skills. Tshotsho $(2006,1)$ believes that tertiary-level South African learners face additional difficulties when writing in English, particularly when the language is foreign to them, and that these learners have not yet attained adequate levels of proficiency to encourage them to cope with written English as used in the academic communication channel. Banda $(2003,118)$ was also concerned about the standards of academic writing amongst learners at tertiary level due to the degree of aptitude in the English Language. 


\section{SELF-EFFICACY}

This section discusses the idea of Self-efficacy, as extended to the academic programme for CMA learners, particularly individuals who are experiencing problems academically. The emphasis will be on the dependent variable of Self-efficacy in learners. The concern is why some learners demonstrate higher degrees of self-confidence in their aptitudes, while others seem less confident of themselves. The answer to the difference between these two extremes could be attributable to the Self-efficacy of a student's belief in his or her capacity to perform tasks. There is a growing body of research revealing an optimistic noteworthy connection between Self-efficacy beliefs and academic performance. The current chapter charts the focal enhancements, the most crucial and continuing features and claims of Self-efficacy in understanding and using the concept in a knowledgeable way. The next section focuses on the role that Self-efficacy plays on an individual.

\section{Self-efficacy role}

Nearly everybody can decide on objectives that they would like to achieve, aspects they would really like to improve upon and things they would really like to accomplish. Nevertheless, most people do know that it is not as easy as people think to initiate such schemes into effect. Bandura and several others investigated and found that the Self-efficacy of a person plays a critical role in the way to manage goals, tasks and challenges. Bandura and others have researched and found that an individual's Self-efficacy plays a key role as to how to manage goals, tasks and challenges. Cherry (2018) highlights that those learners who have a robust awareness of Selfefficacy:

- Vision thought-provoking difficulties as responsibilities to be grasped;

- $\quad$ Mature a deep sense of attention in the actions in which they take part;

- $\quad$ Develop a deeper understanding of their desires and behaviours; and

- $\quad$ Make progress speedily from hindrances and displeasures.

Cherry (2018) also believes that those learners with a fragile common sense of Self-efficacy:

- $\quad$ Evade thought-provoking errands;

- Assume that problem activities and circumstances are beyond their ability;

- $\quad$ Concentrate on moral weaknesses and negative consequences; and

- $\quad$ Extremely quickly run the risk of losing trust in personal skills. 
Furthermore, even when the actual ability levels are the same, learners with high Self-efficacy have the tendency to learn and achieve more than persons with low self-efficacy, (Ormrod 2008, 137). The next section focus on the attainment of self-efficacy.

\section{Self-Efficacy sources}

In attempting to increase the Self-efficacy of learners, it is firstly important to identify and understand its sources. Cherry (2018) suggests that early childhood Self-efficacy continues to grow as youngsters cope with an extensive range of encounters, activities and circumstances. Nevertheless, Self-efficacy improvement did not necessarily conclude throughout early phases, but continues to expand throughout entire lives as people gain new talents, interactions and the ability to understand (Cherry 2018). The sources of Self-efficacy stem from the learner's variety of experiences throughout their life.

The primary research focus of Bandura's early work was on the tendency and ability of learners to understand and adjust their actions by vicarious interaction and social modelling, instead of by actual experience. Bandura (1994, 71-72) advocates that Self-efficacy beliefs are formed according to how people perceive the feedback they receive from four sources:

i. Past Performance (Bandura claims that one of the most powerful ways to build a clear sense of success would be through interactions of mastery);

ii. Modelled Behaviour;

iii. Social Persuasion or Feedback from others; and

iv. Physiological Responses.

\section{Self-efficacy dimension theory of management accounting}

With the discussion on the role of self-efficacy and its sources now comprehensively probed, it becomes essential to consider the relevant dimensions of self-efficacy judgments. Self-efficacy judgments vary on three distinct, but interrelated dimensions and the measurement of selfefficacy relates to these interrelated dimensions. Bandura $(1977,194)$ indicate that these dimensions referred are magnitude, strength and generalizability. Bandura's documented principles on the three dimensions of Self-efficacy as indicated could be appropriate and applied to Management Accounting. The current section explores the impact of these three dimensions of Self-efficacy on Management Accounting.

Management accounting Self-efficacy means assessing the ability to evaluate information correlations and then use historical patterns to forecast and direct business judgments. 
Management Accounting is concerned with historical data or information and utilising the information to make judgments of what must transpire in the future. Moreover, it is not about not only simply collecting information or data, but rather includes formulating conclusions; defining and managing risks; evaluating information and using it for business decisions; planning and budgeting (e.g., compiling written statements or reviewing financial information). The study will explore the dimensions of Management Accounting in the context of Selfefficacy in the section below.

\section{Attainable}

The Management Accounting Self-efficacy magnitude can point towards the level of capability expected to work under pressure, working to deadlines, working long hours and heavy responsibilities. Hence, mistakes in the Management Accounting sphere can be very costly to the organisation. Therefore, learners with a high magnitude of Self-efficacy in Management Accounting may tend to consider themselves as capable of performing more challenging management tasks compared to those with lower Self-efficacy judgments. Put another way, the magnitude of Self-efficacy in Management Accounting could be determined in terms of the levels of support needed to execute a task. Students with a higher degree of Self-efficacy in Management Accounting could consider themselves confident in functioning independently with less support and guidance than those who have less Self-efficacy judgments.

\section{Generalisability}

Self-efficacy generalizability reflects on the degree to which the judgment is limited to a particular domain of activity as indicated by Bandura. Within the Accounting context, these domains may well be considered to reflect analytical, advisory, decision-making and soft skills of trained management accountants.

As a result, learners with high degree of Management Accounting Self-efficacy generalisability will be able to use a wide range of skills competently. The range of skills are namely in Identifying and Managing Risks; Analysing Information (using it to make business decisions); Planning and Budgeting. However, those with low Management Accounting Selfefficacy generalisability would perceive their capabilities as limited to particular aspects of Management Accounting.

\section{Strength}

The strength of Management Accounting Self-efficacy judgment relates to the level of trust about the decision, or the confidence that a learner has regarding their ability to perform the 
various tasks as discussed above. Thus, not only would learners by way of high Management Accounting Self-efficacy perceive themselves as able to accomplish more challenging tasks (high magnitude), but the learners would demonstrate better confidence about their ability to successfully perform each of the activities.

\section{Self-efficacy psychological processes and learner performance}

Self-efficacy can affect the learner's performance through four major psychological processes. According to Bandura (1994, 72-75), these four major processes are the cognitive, motivational, affective and selection processes.

\section{Cognitive/Rational process}

The learners' confidence in their ability effects the cognitive process by influencing the proactive scenarios that humans construct and rehearse (Bandura 1994, 72). For instance, learners with elevated Self-efficacy beliefs are likely to anticipate success scenarios, while those with little Self-efficacy beliefs have a tendency to dwell on things that can go wrong and anticipate failure. In short, Self-efficacy influences analytic thinking (Bandura 1994, 73). Occasionally, high Self-efficacy can however contribute to less effort being utilised into a specific task by learners.

The reason is that high Self-efficacy can often contribute to over-confidence in the intellectual ability of the learners, generating a false perception of potential. Redmond (2010 cited in Tinsley 2019) indicates that the result is due to the learner thinking they know more about the task than the learner really does and failing to apply the necessary effort. Bandura (1993, 120-128) argues that the factors affecting cognitive functioning are capacity generation, social comparative effects, feedback framing, perceived controllability and casual structure.

\section{Motivation process}

In the motivation process, Self-efficacy now affects motivation by defining the goal level, determination and resistance to shortcomings (Bandura 1994, 73). Students with an elevated sense of Self-efficacy appear to set higher goal rates than those who have weak Self-efficacy, resulting in a propensity to exert greater effort. Similarly, learners with lower Self-efficacy usually point to a lack of expertise, whereas those with strong Self-efficacy tend to refer to a lack of commitment. As a result, those with little Self-efficacy have a tendency to give up in challenging circumstances (Bandura 1994, 73). On the other hand, those with high Self-efficacy persevere in difficult circumstances (Bandura 1994, 73). 


\section{Affective/Emotional process}

Self-efficacy, on a number of fronts, influences affective processes, which regulate emotional states and stimulate emotional or physiological reactions. Bandura $(1994,75)$ argues that a poor sense of effectiveness for exercising stressor regulation triggers autonomic reactions, catecholamine secretion and endogenous opioid release. Conversely, those with a stronger sense of self-regulatory effectiveness have a tendency to be more successful in reducing healthimpaired behaviours and integrating health-promoting habits into their lifestyles (Bandura $1994,75)$.

\section{Selection process}

Self-efficacy also influences selection processes, which suggests that Self-efficacy influences the kinds of tasks and conditions the students select. Bandura $(1994,75)$ highlights that learners will evade situations that they believe are beyond their capabilities, but readily take on challenges that they perceive themselves to be capable of handling. Hence, learners will choose the environments in which they exist and influenced by those environments. Bandura (2004, 616) highlights that individual functionality seems to be the result of the dynamic interplay of psychological, behavioural, and environmental factors. Such relationships between the different fields of human experience is the basis for Bandura's conception of reciprocal determinism. The environment or the learner's situational characteristics affect behaviour in a given situation and which in turn behaviour affects the environment or the learner's situational characteristics. As a final point, cognitive and personal factors influence behaviour and in turn affect those same factors.

\section{METHODOLOGY}

\section{Research design}

Human sciences distinguish two basic research methods or methodologies for the collection of data, namely qualitative and quantitative methodology or methodological models. Both methods make use of explicit techniques to collect data and these include literature reviews, interviews, questionnaires and direct observation (Zikmund et al. 2013, 134). The current research article was predominately quantitative in nature.

\section{Sampling design}

The populations that frequently concern human behavioural scientists are so enormous that scholars must therefore get a hold of data from only one sample of this population and before 
drawing a population sample for analysis, researchers should obtain clarity regarding the population or units of analysis to which their research hypotheses apply (Quinlan 2011, 143). Therefore, the target population considered for the current study were first year learners registered for Cost and Management Accounting at Mangosuthu University of Technology (MUT) and Durban University of Technology (DUT) and all DUT and MUT Management Accounting lecturers.

\section{Sampling techniques}

Probability sampling consists of individuals or elements having an equal probability of being selected. A survey consists of accumulating quantitative information about participants in a population, and often results in enough respondents to have an above average degree of statistical confidence. It was therefore decided that probability sampling and a census survey is considered a more appropriate method and relevant to the present study.

\section{Sample size}

The sample size that was deemed appropriate for the study are as follows:

- The control group:

The first year learners registered for Cost and Management Accounting at MUT.

- The experimental group:

The first year learners registered for Cost and Management Accounting at the DUT.

\section{Data collection method}

The administration of the questionnaires took place at two stages. The first stage was at the time of the learners' enrolment and then a follow up took place towards the completion of the learners' second year of study. The researcher carried out the dissemination and collection of the questionnaires of all the respondents.

\section{Data analysis}

In the present study, the inferential statistics that was used included Cronbach Alpha, Correlation Analysis, Bar charts, Cross-tabulations, T-tests and ANOVA. The quantitative data was captured using the computer software package known as Statistical Package for Social Sciences (SPSS) under the guidance of a statistician. The quantitative data analysis was performed using Predictive Analytic Software (PASW) Statistics. 


\section{FINDINGS}

In order to determine the level of Self-efficacy of learners prior to undertaking the General Education Modules and those who are not undertaking the General Education Modules was composed around eight categories on self-efficacy:

i. Problem-Solving and Logical Reasoning;

ii. $\quad$ Learning and Performance;

iii. Perceived academic control;

iv. $\quad$ Self-Learning (Note-Taking);

v. Self-Learning (Studying);

vi. Self-Learning (Test Preparation);

vii. $\quad$ Self-Learning (Reading); and

viii. Self-Learning (Writing).

\section{Findings 1}

The results indicated similarities between the level of Self-efficacy of learners prior to undertaking the General Education Modules and those who were not part of the implementation of the General Education Modules.

\section{Findings 2}

The results revealed that there were differences in the level of Self-efficacy of learners after undertaking the General Education Modules as compared to the level of Self-efficacy of learners who did not undertake the General Education Modules.

\section{Findings 3}

The results in the pre-test (Self-efficacy) scores of the group that undertook the General Education Modules as compared to the group who did not undertake the General Education Modules revealed no significant difference.

\section{Findings 4}

The results between the pre-test (Self-efficacy) scores and post-test (Self-efficacy) scores of the group that undertook the General Education module revealed a significant percentage difference $(+9.1 \%)$ as indicated in Figure 1. 


\section{Findings 5}

The results between the pre-test (Self-efficacy) scores and post-test (Self-efficacy) scores of the group that did not undertake the General Education Modules revealed no significant difference.

\section{Findings 6}

The results between the post-test (Self-efficacy) scores of the group that undertook the General Education module and the group that did not undertake the General Education modules revealed a significant difference in support of the group that undertook the General Education module.

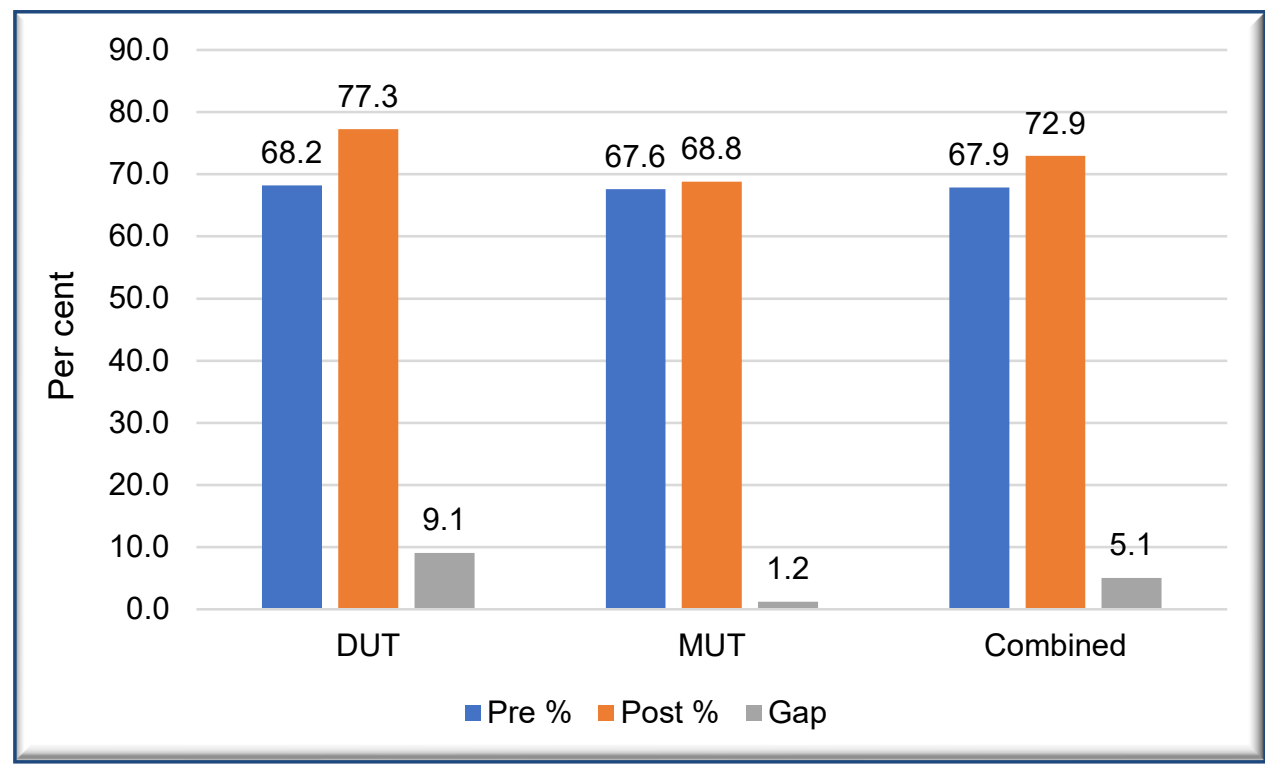

Figure 1: Overall Gap Analysis between Pre-Test and Post-Test

\section{DISCUSSION}

The current section highlights an intervention strategy that DUT could implement to identify at risk learners at an early stage of enrolment.

\section{General education intervention strategy}

An intervention strategy signifies that there is a problem and problem-solving encompasses several steps. The steps essentially reflect the methodical approach for defining and describing a problem; generating potential solutions; and implementing, monitoring and evaluating the effectiveness of the selected intervention. It is therefore imperative that the design and implementation of the intervention strategy focuses on the needs of the learner. The suggested intervention strategies and plan of action for implementation to enhance learners' performance are as follows: 


\section{Screening and assessment model}

It is essential to universally screen and assess for academic difficulties before learner enrolment into the institution. Depending on the learner's performance in the screening and assessment outcome, lecturers can select instructional programmes and provide the necessary intervention. The institution or department can screen learners via the Standardised Assessment Tests for Accessing and Placement, commonly known as SATAP. The Standardised Assessment Testing for Accessing and Placement can be utilised for assessing performance on General Education aspects such as: (i) Communication; (ii) Critical Thinking; (iii) Quantitative Analysis; (iv) Research and Information; and (v) Computer Literacy. The institution or department can make use of SATAP in combination with Grade 12 results in order to ascertain whether the learner has an aptitude or needs intervention. The main aim of the test should be for placement and diagnostic purposes. The outcome of the test can also be utilised to identify any shortfall of skills, as well as if the learner needs any additional intervention.

The screening and assessment model that the institution selects should include the following four basic components:

i. Screening and assessment that focuses on learner skills/needs rather than classification;

ii. Assessing response to instruction, rather than relying on norm-referenced comparisons;

iii. Using evidence-based strategies within General Education; and

iv. Fostering a collaborative partnership amongst general and special lecturers for consultation and team decision-making.

\section{Institutional support programme}

The institution's support programme should provide sufficient learner support to be successful and improve academic performance. Learner support should include but not be limited to mentorship, coaching, counselling and tutorials. Academic support to learners can be by way of additional instructional time, remedial courses and extended learning programmes. Remedial courses should include the General Education components such as Communication, Critical Thinking, Quantitative Analysis, Research and Information and Computer Literacy. Qualified and dedicated individuals or tutors should carry out the support programmes.

The response to intervention ought to align with the steps of the institution's screening and assessment model:

i. Employing evidence-based interventions; 
ii. Regularly measuring a learner's progress to determine whether the intervention is effective;

iii. Assessing the quality of the instructional strategy; and

iv. Assessing the reliability of its implementation. For example, has the intervention worked? Was the intervention scientifically constructed and executed as planned?

\section{CONCLUSION}

In any research article, in addition to the problem statement that is being scrutinised, it is equally significant that the researcher provides an intervention strategy that will address the issue at hand. The research article at hand concludes by providing such a strategy.

\section{REFERENCES}

Abedi, J. and C. Lord. 2001. "The language factor in Mathematics tests." Applied Measurement in Education 14(3): 219-234.

Bandura, A. 1977. "Self-efficacy: Toward a unifying theory of behavioural change." Psychological Review 84(2): 191-215.

Bandura, A. 1993. "Perceived self-efficacy in cognitive development and functioning." Educational Psychologist 28(2): 117-148.

Bandura, A. 1994. "Self-Efficacy." In Encyclopedia of human, ed. V. S. Ramachaudran, 71-81. New York: Academic Press.

Banda, F. 2003. "A survey of literacy practices in black and coloured communities in South Africa: Towards a pedagogy of multiliteracies." Language, Culture and Curriculum 16(2): 106-129.

Bandura, A. 2004. "Swimming against the mainstream: The early years from chilly tributary to transformative mainstream." Behaviour Research and Therapy (42): 613-630.

Bernstein, B. 2003. Class, Codes and control: The structure of pedagogic discourse. $4^{\text {th }}$ Edition. London: Routledge.

CDE see Centre for Development and Enterprise.

Centre for Development and Enterprise. 2014. Young people and opportunity in South Africa's cities. Johannesburg: Centre for Development and Enterprise.

Cheng, K. W. 2007. "The curriculum design in universities from the perspective of providers in accounting education." Education 127(4): 581-590.

Cherry, K. 2018. What is Self-Efficacy? https://www.verywell.com/what-is-Self-efficacy-2795954. (Accessed 26 September 2018).

De Klerk, V. 2000. "To be Xhosa or not to be Xhosa ... that is the question." Multilingual and Multicultural Development 21(3): 198-215.

Department of Basic Education. 2014. National senior certificate examination 2014: diagnostic report. Pretoria: Department of Basic Education.

Evans, R. and A. Cleghorn. 2014. "Parental perceptions: A case study of school choice amidst language waves." Education 34(2): 1-19.

Fakeye, D. and O. Yemi. 2009. "English language proficiency as a predictor of academic achievement among EFL learners in Nigeria." Scientific Research 37(3): 490-495.

Floyd, B. 2014. Accounting and accountants: 6 common misconceptions. http://www.ccsd.edu/blog/Accounting-and-accountants-6-common-misconceptions. (Accessed 26 September 
2018).

Gardiner, M. 2008. "Education in rural areas." Issues in Education Policy 4: 1-34.

Hofmeyr, J. 2012. "Learn to read." Independent Education 5 September: 1. http://www.ieducation. co.za/learn-to-read/. (Accessed 5 March 2018).

National education evaluation and development unit. 2013. NEEDU National Report 2012: The State of Literacy Teaching and Learning in the Foundation Phase. Pretoria: National Education Evaluation and Development Unit.

NEEDU see National Education Evaluation and Development Unit.

Nel, N. and H. Muller. 2010. "The impact of teachers' limited English proficiency on English second language learners in South African schools." Education 30: 635-650.

Ngidi, S. A. 2007. "The attitudes of learners, educators and parents towards English as a language of learning and teaching (Lolt) in Mthunzini circuit." M. Arts, University of Zululand. http://uzspace.uzulu.ac.za/handle/10530/80. (Accessed 29 September 2018).

Ormrod, J. E. 2008. Human learning. $5^{\text {th }}$ Edition. Upper Saddle River, New Jersey: Pearson Education.

Perumal, J. 2009. "Reading and creating critically leaderful schools that make a difference: The postapartheid South African case." Leadership in Education 12(1): 35-49.

Quinlan, C. 2011. Business research methods. Mason, Ohio: South-Western Cengage Learning.

Rammala, J. R. 2002. "Language planning and social transformation in the Limpopo Province: The role of language in education." DLitt thesis, University of Pretoria. http://repository.up.ac.za/ handle/2263/25725. (Accessed 28 August 2018).

Ramos, J. T. 2010. "A study on schema activation, summarizing, and critical evaluation as predictors of writing proficiency." Research and Review 5(1): 31-39.

Rauchas, S., B. Rosman, J. Konidaris, and I. Sanders. 2006. "Language performance at high school and success in first year computer science." Proceedings of SIGCSE 2006. Houston.

Surty, E. 2011. "Quality education for rural schools in South Africa: challenges and solutions." South African Rural Educator 1: 8-15.

Swanepoel, E. 2017. "The real matric marks." News24 8 January. https://www.news24.com/ SouthAfrica/News/the-real-matric-marks-20170107. (Accessed 20 January 2018).

Taylor, N. 2011. The national school effectiveness study: Summary for the synthesis report. Johannesburg: JET Education Services.

Taylor, N., S. van der Berg, and T. Mabogoane. 2012. What makes schools effective? Report of the national schools' effectiveness study. Cape Town: Pearson Education South Africa.

Taylor, S. and M. Coetzee. 2013. "Estimating the impact of language of instruction in South African primary schools: A fixed effects approach." Stellenbosch Economic Working papers: 21/13. Stellenbosch University: Department of Economics and Bureau for Economic Research.

Tinsley, A. L. 2019. Strengths and weaknesses. https://wikispaces.psu.edu/display/484SU17001/ Strengths+and+Weaknesses. (Accessed 19 July 2019).

Tshotsho, B. P. 2006. "An investigation into English second language academic writing strategies for black learners at the Eastern Cape Technikon." $\mathrm{PhD}$ in Applied Linguistics. http://etd.uwc.ac.za/xmlui/handle/11394/2005. (Accessed 30 September 2018).

Zenex Foundation. 2007. Putting language into the mathematics and science equation. Johannesburg: Zenex Foundation.

Zikmund, W. G., B. J. Babin, J. C. Carr, and M. Griffin. 2013. Business research methods. $9^{\text {th }}$ Edition. Mason, Ohio: South-Western Cengage Learning. 